\title{
RE-KREASI MUATAN FOLKLORE PADA MOTIF BATIK KONTEMPORER DENGAN TEKNOLOGI AUGMENTED REALITY
}

\author{
Motif Batik Lumpia Semarang
}

\author{
Monica Hartanti ${ }^{1}$, Irena Ayu Maitri ${ }^{2}$ \\ Desain Komunikasi Visual, FSRD, Universitas Kristen Maranatha, \\ Jl. Surya Sumantri No. 65, Bandung, Jawa Barat \\ Monica26hartanti@gmail.com
}

\begin{abstract}
Abstrak: Identitas sebuah daerah dapat dibentuk oleh produk budayanya, salah satunya adalah kain Batik. Batik Semarang kontemporer merupakan salah satu produk budaya Kota Semarang yang memiliki keunikan berupa muatan folklore pada motifnya, yang menggambarkan identitas kota Semarang. Disayangkan sebagian besar masyarakat kota Semarang tidak mengetahui folklore yang ada pada kain Batik asal kota mereka. Dari sisi ekonomi hal ini memang tidak menjadi permasalahan, namun bila dilihat dari sisi keberlanjutan warisan budaya, hal ini sebaiknya tidak terjadi. Di era globalisasi, produk budaya perlu dikolaborasikan dengan teknologi, perlu dilakukan re-kreasi bentuk seni masa lalu menjadi sesuatu yang menarik untuk dikonsumsi oleh masyarakat modern. Pengumpulan data dalam penelitian ini menggunakan metode kualitatif berupa wawancara dan observasi langsung mengunjungi pengrajin Batik Semarang dan kuantitatif dengan menyebarkan kuesioner online. Metode transformasi tradisi, cara bertutur Bahasa Rupa dan teknologi augmented reality menjadi teori yang melandasi rekreasi folklore yang ada pada motif Batik Semarang. Melalui Kolaborasi budaya daerah dan teknologi menjadi salah satu alternatif re-kreasi budaya daerah kedalam bentuk media baru yang lebih dekat dengan keseharian generasi muda. Hal ini sebagai juga menjadi upaya keberlanjutan warisan budaya daerah Kota Semarang.
\end{abstract}

Kata kunci: augmented reality, batik Semarang kontemporer, folkore, re-kreasi

Abstract: Cultural products can form the identity of an area, one of which is Batik. Contemporary Semarang Batik is one of the cultural products of the City of Semarang that has a unique form of folklore content on its motives, which illustrates the identity of the city of Semarang. Regrettably, most of the people of Semarang city do not know the content of the folklore on their homemade Batik cloth. From an economic standpoint, this is not a problem, but when viewed in terms of the sustainability of cultural heritage, this should not happen. In the era of globalization, cultural products need to have collaborated with technology; it is necessary to re-create past art forms into something interesting for modern society to consume. The data collected in this study used a qualitative method in the form of interviews and direct observations visiting Semarang and quantitative Batik artisans by 
distributing questionnaires online. The process of transforming traditions, visually using Bahasa Rupa, and Augmented reality technology became the theory that underlies the recreation of folklore in the Batik motif of Semarang. Through the collaboration of regional culture with technology has become an alternative to the re-creation of regional culture into a new form of media that is closer to the daily lives of the younger generation. This is also an effort to sustain the cultural heritage of the city of Semarang.

Keywords: augmented reality, contemporary Semarang batik, folklore, re-creation

\section{PENDAHULUAN}

Pada saat membeli kain batik memang tidak banyak yang mengetahui atau ingin mengetahui makna dari motif pada kain batik tersebut. Sama halnya dengan masyarakat kota Semarang yang membeli produk batik, tanpa mengetahui nama bahkan makna motif yang ada pada batik tersebut, hanya berdasarkan model barang, warna atau pola yang dianggap menarik secara visual saja. Dari sisi ekonomi hal ini memang tidak menjadi permasalahan, namun bila dilihat dari sisi keberlanjutan warisan budaya, hal ini sebaiknya tidak terjadi mengingat Batik merupakan salah satu warisan budaya milik Indonesia yang telah diakui dunia. Hal itu berarti juga bahwa ragam hias yang ada pada motif batik merupakan hasil sebuah ekspresi, imajinasi perorangan atau kelompok yang menyatakan keadaan diri dan lingkungan penciptanya yang dapat menggambarkan cita-cita, makna, dan perasaan yang umumnya sangat dipengaruhi dan erat hubungannya dengan beberapa faktor seperti letak geografis daerah pembuat batik, sifat dan tata penghidupan daerah yang bersangkutan, kepercayaan dan adat istiadat, keadaan alam sekitar, termasuk flora dan fauna, serta adanya hubungan antara daerah pembatikan. Dapat dikatakan bahwa selembar kain batik memuat sebuah identitas asal kain tersebut dibuat.

Identitas sebuah daerah sangat berhubungan dengan kebudayaan yang ada di daerah tersebut. Kebudayaan daerah merupakan bagian dari kebudayaan nasional, sehingga dapat dikatakan bahwa Kebudayaan nasional adalah gabungan 
dari kebudayaan daerah yang ada di negara tersebut yang selaras dengan normanorma berbangsa dan bernegara. (Husamah, 2009). Di era globalisasi ini perlu dengan cermat mengkolaborasikan produk budaya dengan teknologi. Memodifikasi bentuk - bentuk seni yang masih berpolakan masa lalu untuk dijadikan komoditi yang dapat dikonsumsi masyarakat modern. (Agustin, 2011).

Data kuesioner online mengungkapkan bahwa sebanyak $77 \%$ masyarakat Kota Semarang sudah mengetahui eksistensi Batik Semarang; namun 62\% diantaranya tidak mengetahui secara jelas mengenai makna motif Batik Semarang serta folklore yang ada di dalamnya. Hal ini sangat disayangkan dan sebaiknya segera diatasi, karena Batik selayaknya merupakan salah satu identitas dari daerah setempat asalnya sudah selayaknya masyarakat setempat yang paling mengetahui tentang motif batik tersebut. Permasalahan dalam penelitian ini adalah bagaimana mengenalkan kembali folklore yang ada pada motif Batik Semarang kontemporer pada masyarakat kota Semarang, khususnya pada generasi muda.

Tujuan dari penelitian ini adalah mengenalkan kembali folklore pada motif Batik Semarang Kontemporer melalui media baru yang disesuaikan dengan trend teknologi saat ini bagi pada generasi muda kota Semarang khususnya. Hal ini dilakukan juga sebagai upaya keberlanjutan warisan budaya daerah Kota Semarang. Media baru yang dimaksudkan adalah media yang terhubung dengan teknologi. Hal ini menjadi pertimbangan karena dunia saat ini sangat terintegrasi dengan teknologi, oleh karenanya perancang produk digital harus mempertimbangkan orang-orang yang menggunakan perangkat teknologi dalam kehidupan sehari-hari mereka. Teknologi media cetak dan digital memiliki keunggulan masing-masing. Media yang dicetak sifatnya nyata, mudah disimpan untuk digunakan di masa depan, dapat diteruskan kepada orang lain. Digital sifatnya cepat, terlihat lebih masa kini (keren), dapat dipersonalisasi, mudah diakses, dan saat ini semakin banyak digunakan oleh konsumen setiap harinya. 
Ketika media cetak terintegrasi dengan digital akan menghasilkan sesuatu yang bagus, terjadi hubungan simbiosis nyata yang menguntungkan keduanya. (Gould, 2014). Augmented reality (AR) adalah salah satu bentuk media informasi virtual yang dirasakan oleh pemirsa melalui perangkat digital, seperti smartphone. (Kendra dalam Scholz \& Smith, 2016, bagian 2). Teknologi ini sedang berkembang dengan peluang implementasi di banyak pasar yang berbeda. (Kendra dalam Javorik, 2016, bagian 2.1). Re-kreasi folklore yang ada pada motif Batik Semarang kontemporer menggunakan teknologi AR memiliki beberapa fungsi, yaitu sebagai alat pemasaran yang mampu menghadirkan faktor kekinian yang nyata bagi konsumen, sehingga membuat produsen atau pengiklan menjadi tertarik untuk memasukkan pesan tertentu dalam konten AR-nya dan juga sebagai salah satu upaya keberlanjutan folklore Kota Semarang yang disampaikan dengan cara yang lebih kreatif, kekinian sehingga mudah diterima oleh masyarakat.

\section{METODE PENELITIAN}

Pengumpulan data dalam penelitian ini menggunakan metode wawancara dan observasi langsung ke Kampung Batik Semarang, Sanggar Batik Semarang 16 dan Batik Zie untuk mengetahui asal usul penciptaan motif Batik Semarang dan makna dari motifnya. Selain itu disebarkan juga kuesioner online dengan sampel 40 motif batik Semarang Kontemporer kepada 140 orang responden dengan rentang usia 17-56 tahun baik yang lahir, tinggal, maupun pernah menetap di Kota Semarang. Dalam perancangan karya yang di re-kreasikan, studi pustaka yang mendukung hasil akhir dari penelitian ini adalah metode transformasi tradisi ATUMICS dan teori Bahasa rupa dan macam folklore.

\section{Studi Literatur}

Metode Transformasi Tradisi- ATUMICS 


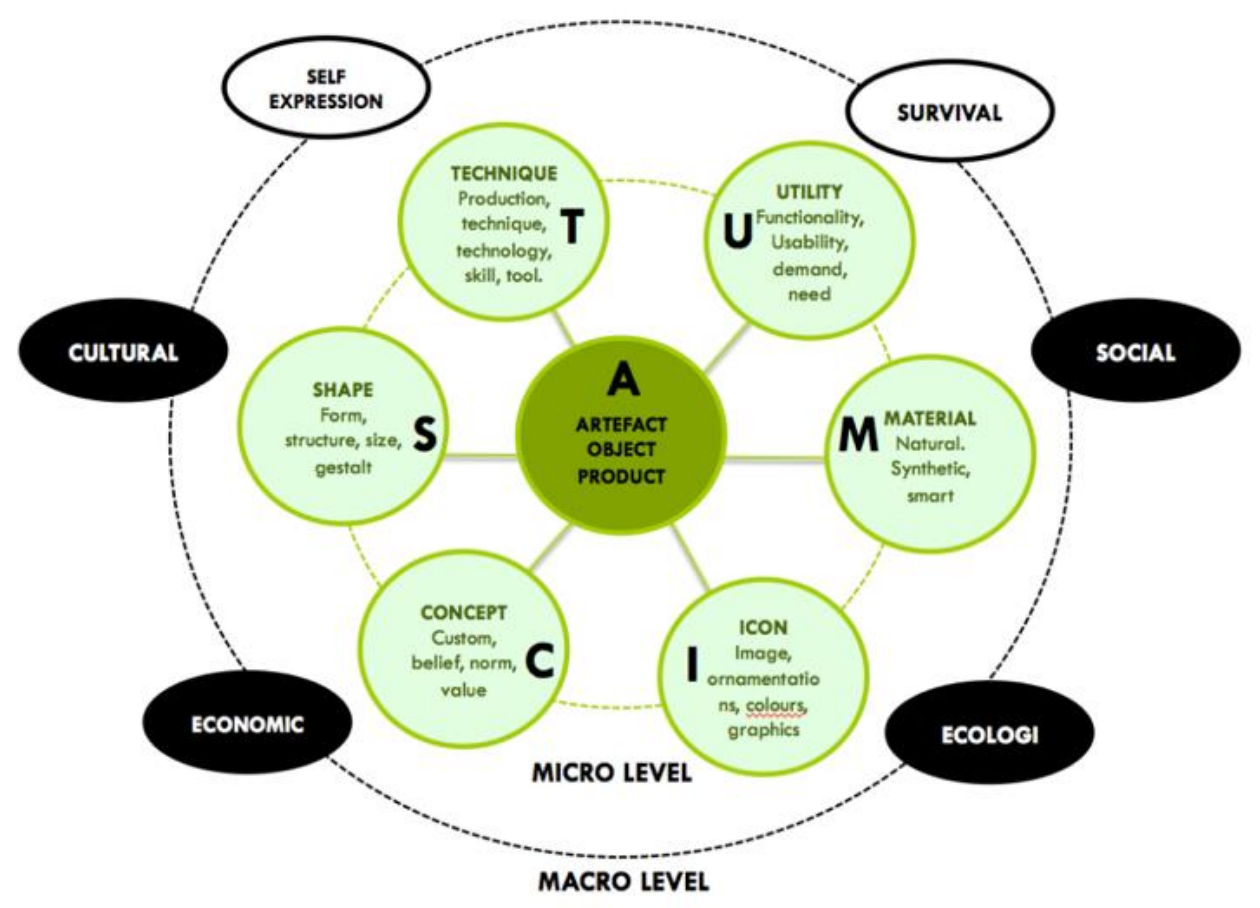

Gambar 1 Metode ATUMICS

Sumber: Nugraha, 2012

ATUMICS adalah sebuah metode untuk mentransformasikan budaya tradisional ke bentuk produk baru yang modern. Kata transformasi berasal dari sebuah proses membentuk ulang, memodifikasi atau mengkonversi dalam sebuah manifestasi yang beragam. Metode ini memandang sebuah artefak, objek, atau produk memiliki 2 level utama eksistensi, yaitu level mikro dan level makro. Keseluruhan struktur dari metode ATUMICS, dengan elemen dasarnya dan enam aspek motivasi, dipengaruhi oleh model yang diajukan oleh Victor Papanek, Pirkko Anttila, Ahadiat Joedawinata, dan Rebecca Reubens.

Level Mikro terdiri dari Technique - teknik produksi, teknologi, skill, alat. Utility - fungsionalitas, kegunaan - permintaan (demand), kebutuhan. Material bahan alami, bahan sintetik, bahan smart. Icon - gambar, ornamentasi, warna, grafis. Concept - adat, kepercayaan, norma, nilai. Shape - bentuk, struktur, ukuran, gestalt. Pada Level Makro sebuah artefak dipandang sebagai konsekuensi dan motivasi yang mendasari pembuatannya. Motivasi memberikan objek suatu 
landasan filosofis tentang alasan objek tersebut diciptakan. Makro level terdiri dari enam aspek, yaitu: ekspresi-diri, survival, budaya, sosial, ekonomi, dan ekologis dan semuanya saling terkoneksi. Empat di antaranya yang dianggap penting dalam merepresentasikan 4 pilar sustainability (keberlanjutan), yaitu motivasi ekonomi, sosial, budaya, dan ekologis. Penjelasan enam aspek yang ada pada level makro adalah sebagai berikut:

\section{a. Motivasi ekonomi}

Ekonomi sangat penting untuk mendukung keberlangsungan kehidupan dan kualitas kehidupan, dan membuat hal-hal terus berlangsung. Sebuah masyarakat atau negara akan berada dalam kesulitan jika ekonomi mengalami krisis serius. Walaupun sangat berkuasa, ekonomi tidak bisa hanya menjadi satusatunya motivasi untuk menghasilkan produk. Dalam prinsip metode ATUMICS, motivasi ekonomi harus diimbangi dengan motif lain seperti budaya, sosial, atau ekologis untuk menciptakan keseimbangan yang optimal. Dalam konteks pengrajin individual dan desainer-pembuat, ekonomi terutama bermakna untuk mencari nafkah dengan menghasilkan dan menjual objek atau produk. Di samping keuntungan pribadi, isu ekonomi dapat dipandang dari skala yang lebih besar, misalnya, bagaimana revitalisasi produk tradisional dapat berkontribusi bagi ekonomi yang berkelanjutan dari komunitas tertentu, dan bahkan meningkatkan penghasilan mereka.

\section{b. Motivasi sosial}

Aspek sosial berurusan dengan komunitas dan masyarakat. la mengacu pada interaksi antara individu-individu yang berlainan, dan masyarakat yang berbeda. Gagasan untuk memasukkan aspek sosial diedarkan pada pertimbangan bahwa hal ini dapat menjadi keuntungan bagi masyarakat bila banyak kreasi artefak memiliki koneksi dengan kehidupan sosial mereka. Sebuah objek dapat dirancang sehingga dapat melibatkan keterikatan sosial. Tujuan motivasi sosial 
adalah meningkatkan interaksi sosial dan kerjasama, untuk mendukung keberlangsungan masyarakat, dengan menggunakan kecerdasan dan kreativitas mereka, seniman dan desainer dapat mengusulkan aktivitas desain terkait yang menopang sejenis komunitas yang berlandaskan produksi lokal, jasa, dan industri.

\section{c. Motivasi Budaya}

Peran dari budaya adalah vital dan menjadi motivasi utama bagi berbagai ciptaan seni, kriya, dan objek desain. Dalam pengembangan, sistem baru dan artefak baru dapat secara efektif berkontribusi untuk mempertahankan masyarakat hanya jika mereka dapat menyesuaikan diri dengan kebiasaan, spirit, norma, dan budaya lokal. Dengan kata lain, setiap aplikasi baru yang beroperasi tanpa korelasi dengan budaya tradisional atau lokal cenderung untuk tidak bertahan. Objek asing atau tak dikenal yang tak berakar pada tradisi lokal mungkin memunculkan resistensi dari masyarakat lokal. Karya yang menekankan motivasi budaya mungkin tampak seperti mengembangkan identitas budaya, atau mendokumentasikan pengetahuan asli dan mengajukan pengembangan berkelanjutan yang memungkinan yang didasarkan pada sumber dan tujuan lokal. Di level makro, budaya dipandang sebagai sebuah motivasi, yang berasal dari pertimbangan keberlanjutan, bukan hanya menyediakan konsep semata.

\section{c. Motivasi Ekologis}

Pengembangan berkelanjutan dalam ekologi bermakna bahwa kemampuan mempertahankan dan memanfaatkan sumberdaya yang ada untuk hari ini dan generasi masa depan tanpa mengurangi kualitas mereka. Saat ini, hampir setiap aktivitas memerlukan pertimbangan aspek ekologis. Bisnis dan industri mulai memasukkan ekologi sebagai bagian dari tujuan mereka. Tantangan terbesar yang harus dihadapi tampaknya adalah bagaimana menciptakan produkproduk ekologis yang sehat tanpa mengorbankan keuntungan dan nilai ekonomi. 


\section{d. Motivasi Survival}

Istilah 'survival' menunjuk pada keadaan terus hidup atau ada; yang seringkali berada dalam kesulitan atau bahaya. Istilah ini diadopsi dari model 'Functional Complex' dari Papanek (1984), yang menyatakan bahwa setiap kebutuhan dasar manusia untuk menciptakan artefak adalah untuk bertahan hidup. Walaupun jarang muncul dalam kehidupan modern, beberapa tindakan tertentu dari transformasi tradisi mungkin mencerminkan tujuan untuk bertahan hidup.

\section{e. Motivasi Ekspresi diri}

Ekspresi diri adalah motivasi umum yang muncul dari karya seni. Kebanyakan seniman dan pengrajin berpikir bahwa motivasi utama bagi karyanya adalah bagi ekspresi diri yang kreatif. Akan tetapi, walaupun fokusnya pada ekspresi diri, beberapa seniman mungkin memiliki beberapa motif. Beberapa karya seni mungkin mencerminkan pada saat yang sama ekspresi artistik kreatif dan kritik sosial. Beberapa mengkombinasikan ekspresi artistik dengan isu lingkungan, yang lain mungkin menempatkan penekanan pada budaya dan tujuan ekonomi (Nugraha, 2012).

Melalui metode transformasi tradisi ini, folklore pada batik Semarang akan dikreasikan kembali dalam bentuk media yang berbeda dengan yang sudah ada dan sesuai dengan era digital dengan cara dipetakan terlebih dahulu ke dalam level mikro dan level makro. Meminjam pendapat dari Bapak Adi Nugraha dalam seminar nasional Unoflatu 2019, bahwa budaya daerah perlu terus di re-kreasikan agar tetap dikenal oleh masyarakat saat ini, sehingga budaya tersebut tetap hidup. 


\section{Bahasa Rupa}

Dalam tulisan ini, perlu dibahas sedikit tentang Bahasa rupa yang digunakan sebagai cara bertutur dalam visualisasinya. Bahasa rupa merupakan media belajar yang memerlukan partisipasi aktif pembaca karena memancing adanya imajinasi dan pembaca menjadi turut berpikir. Selain dengan gambar anak, Bahasa rupa memiliki kedekatan dengan gambar prasejarah, primitif, dan seni lukis avant garde, seperti karya lukisan Picasso atau relief pada candi, yang berusaha menjelaskan secara detail sebuah cerita melalui gambar. Hal itu disebabkan karena pada zaman dahulu sebelum ditemukan adanya tulisan, gambar menjadi alat komunikasi yang merepresentasikan bahasa kata melalui rangkaian gambar terungkap.

Dua sistem menggambar dalam prinsip Bahasa rupa, yang pertama adalah NPM (Naturalis-Perspektif-Momen opname) dari barat yang melalui kolonialisme berglobalisasi ke seluruh dunia. NPM "menembak" dari satu arah, satu jarak, satu waktu "ceklik" seperti memotret. NPM berupa gambar jadi adegan yang merupakan gambar mati (still picture), memenangkan kesan ruang, tapi kehilangan dimensi waktu, karena itu gambar NPM tak banyak bisa bercerita, NPM lebih mendeskripsikan apa yang digambar. Kedua, RWD (Ruang Waktu Datar) dari tradisi. Menembak dari aneka arah, aneka jarak, aneka waktu. Bisa menggambar gerak; objek yang sama bisa digambar beberapa kali; tidak memakai perspektif; yang penting diperbesar; bisa ada beberapa lapis latar; tiap objek dan latar punya ruang dan waktu sendiri sendiri, tapi kesemuanya bisa menjadi bagian dari tema satu lukisan. Ilustrasi yang digunakan dalam karya ini menerapkan prinsip-prinsip bahasa rupa RWD (Ruang Waktu Datar) (Tabrani, 2009).

Adapun prinsip penerapan bahasa rupa RWD dijelaskan lebih detail oleh Tabrani (2014: 68-76) sebagai berikut: Pertama, Cara Ruang Angkasa : Tidak 
memiliki batas jelas wilayah seperti atas-kanan-kiri-bawah, nampak seperti melayang. Kedua, Cara Diperbesar dan Diperkecil: Memperbesar objek/peristiwa yang penting dan memperkecil objek/peristiwa yang kurang penting. Ketiga, Cara Perwakilan: Hanya menggambarkan perwakilan yang penting saja. Objek juga digambarkan secara utuh dari kepala hingga kaki. Keempat, Cara Sinar $\mathbf{X}$ : Tembus pandang, yang 'di dalam' bisa digambar dari 'luar'. Kelima, Cara Menggambar Waktu \& Kembar (Aneka Tampak): Objek yang berpindah tempat dan waktu (cara kembar) dengan posisi objek digambarkan beberapa kali pada tempat dan waktu yang berbeda-beda. Keenam, Cara Menggambar Tanpa Perspektif: Tidak menuju pada suatu titik hilang, sehingga suatu objek yang seharusnya tidak terlihat secara logis atau titik terjauh sekalipun dapat diceritakan. Ketujuh, Cara Rebahan (Berkeliling): Objek direbahkan atau dibuat berkeliling agar dapat terlihat serta menceritakan sesuatu dengan detail. Terakhir, Cara Aneka Tampak: Penggambaran objek dengan aneka tampak.

\section{Folklore}

Folklore adalah bagian dari kebudayaan, apapun bentuk dan wujudnya, diciptakan atau dikreasikan oleh manusia (man-made). Folklore dari generasi ke generasi diwariskan melalui lisan atau setengah lisan. Folklore diambil dari Bahasa Inggris yang berarti kolektif (folk) dan (lore) yang berarti tradisi. Dengan demikian, folklore dapat diartikan sekelompok orang yang memiliki ciri pengenal fisik, sosial, kebudayaan tertentu sehingga dapat dibedakan dari kelompok yang lain. Biasanya kelompok tersebut telah memiliki suatu tradisi yakni kebudayaan yang telah diwarisi turun-temurun (sedikitnya dua generasi) yang dapat diakui sebagai milik bersama. Folklore juga dapat menunjukkan identitas si pemakainya. (Seliriana, 2012:74). 
Secara garis besar, folklorist Jan Harold Brunvard (1968) membagi folklore ke dalam tiga jenis, antara lain: Pertama, Folklore lisan atau verbal, narasi tradisional, kebanyakan folklore masuk ke dalam jenis ini. Penyebarannya dilakukan secara oral dari mulut ke mulut dan biasanya tidak dicatatkan. Contohnya: bahasa rakyat, proverb atau peribahasa, tebakan, puisi, cerita rakyat, atau prosa rakyat. Prosa biasanya dibagi lagi menjadi mitologi, legenda, dan dongeng (fairy tale). Kedua, Folklore sebagai perilaku, kegiatan yang sifatnya behavioral atau sosiofact (fakta sosial) sebagai contohnya adalah kepercayaan, upacara-upacara atau ritual seperti ritual kelahiran, kematian, dan pernikahan, adat dan kebiasaan yang sifatnya costumary, tari-tarian, teater, permainan daerah. Ketiga, Folklore bukan lisan atau artefak, artefak dalam pengertian umum adalah sesuatu yang dibuat manusia dan memiliki informasi kultural akan si pembuat atau pemakainya. Contohnya artefak arsitektural (bangunan, rumah daerah, tempat penyimpanan mayat, altar pemujaan atau ritual, pakaian, makanan-minuman daerah, kesenian, senjata atau alat-alat seperti perkakas, peti mati, dan alat musik (elib.unikom.ac.id, 2017). Adapun Ragam hias Batik Semarang kontemporer pada motifnya mengandung keunikan folklore lisan dan artefak dari Kota Semarang.

\section{HASIL DAN DISKUSI}

\section{Batik Semarang Tempo Dulu dan Kontemporer}

Sebelum membahas re-kreasi yang dilakukan pada salah satu motif Batik Semarang kontemporer, berikut ini adalah sekilas tentang Batik Semarang tempo dulu dan kontemporer. Semarang merupakan salah satu pusat perdagangan besar di Indonesia yang terletak di daerah Pantai Utara Jawa. Letak geografis ini yang menjadikan Kota Semarang sempat sebagai salah satu sentra batik di Jawa Tengah. Walaupun sampai saat ini Batik Semarang tidak sepopuler batik Jawa Tengah 
lainnya, akulturasi budaya yang terjadi di kota Semarang menghasilkan keunikan motif batik yang merupakan perpaduan batik keraton (Vorstenlanden) dan batik pesisir dengan percampuran kebudayaan pendatang yaitu Tionghoa dan Arab. Kedatangan Jepang di Semarang tahun 1942, melumpuhkan banyak aktivitas ekonomi di kota itu, termasuk sektor batik (Brommer, dkk., 1995: 40-41). Kampung Batik pun menjadi sasaran pembakaran, meskipun belum seluruhnya musnah. Ditambah dengan peristiwa Pertempuran Lima Hari di Semarang antara pemuda Indonesia dan tentara Jepang yang berlangsung pada 15-19 Oktober 1945 , tentara Jepang membakar rumah-rumah penduduk di kampung-kampung di Kota Semarang, Kampung batik salah satunya.

Beruntung, masih ada perusahaan batik bernama "Tan Kong Tien Batikkerij milik orang Cina peranakan di Kampung Bugangan, yang berkembang sejak awal abad ke-20 sampai tahun 1970-an. Pada masa Kolonial Belanda "Batikkerij Tan Kong Tien" termasuk dalam kategori batik premium, karena pemesannya berasal dari kalangan pejabat pemerintahan, turis, dan pedagang. Pada tahun 1970 perusahaan batik Tan Kong Tien surut karena tidak ada lagi generasi penerusnya. (Yuliati, 2010). Sepuluh tahun kemudian, dimulai tahun 1980 muncul perajin batik Semarang kontemporer antara lain batik "Sri Retno", Sanggar Batik Semarang 16 dan Batik Zie yang mengembangkan ikon kota Semarang, dan juga menciptakan motif Propagul (Yuliati,2010). 
Data hasil kuesioner dan wawancara yang telah dilakukan
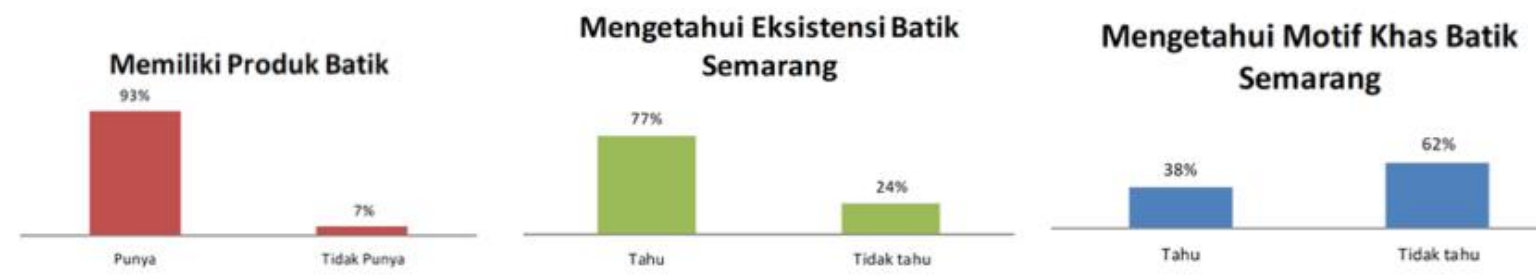

\section{Pengetahuan responden akan folklore pada motif}

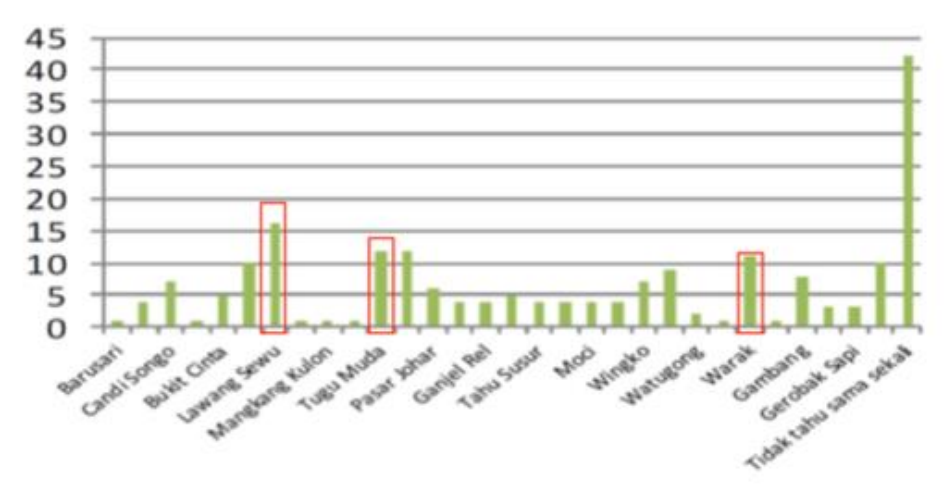

Gambar 2 Diagram hasil kuesioner Sumber: Hartanti dan Maitri, 2018

Para pengrajin batik Semarang saat ini semakin berkurang, walaupun beberapa produsen batik Semarang yang cukup besar seperti Batik Semarang 16 telah melakukan upaya untuk regenerasi pengrajin batik. Sebagian besar masyarakat Semarang cukup mengetahui eksistensi Batik Semarang. Mereka membeli produk batik, tanpa mengetahui nama bahkan makna motif yang ada pada batik tersebut, hanya berdasarkan model barang, warna atau pola yang dianggap menarik secara visual saja. Folklore pada batik yang paling banyak diketahui oleh masyarakat Semarang adalah Lawang Sewu, Tugu Muda, Warak Ngendog.

Pembahasan dalam tulisan ini lebih difokuskan pada motif Batik Semarang kontemporer. Ragam hias pada motif batik Semarang kontemporer mengandung 
keunikan folklore kota Semarang. Sebagai pilot projek dipilih motif Lumpia Semarang yang merupakan folklore bukan lisan. Lumpia Semarang merupakan makanan khas Kota Semarang yang juga sering dijadikan oleh-oleh. Makanan ini merupakan perpaduan citarasa akulturasi China dan Jawa tengah yang dibalut dalam selembar kulit tepung. Bahan-bahan dasar untuk membuat lumpia seperti udang, telur, acar lobak, selada, bawang, dan kulit lumpia, digambarkan pada batik motif lumpia.

Tahapan analisis yang dilakukan adalah sebagai berikut: Pertama, memetakan terlebih dahulu Motif Batik Lumpia Semarang yang belum di re-kreasi menggunakan metode ATUMICS. Kedua, mere-kreasi visual dari Motif Batik Lumpia Semarang menggunakan bahasa rupa yang ditambahkan dengan augmented reality. Ketiga, memetakan hasil rancangan diatas menggunakan metode ATUMICS. Keempat, menganalisis dengan membandingkan keduanya untuk melihat sisi keberlanjutan budaya lokal pada motif batik Semarang.

Tabel 1 Pemetaan Motif Batik Lumpia Semarang dengan metode ATUMICS

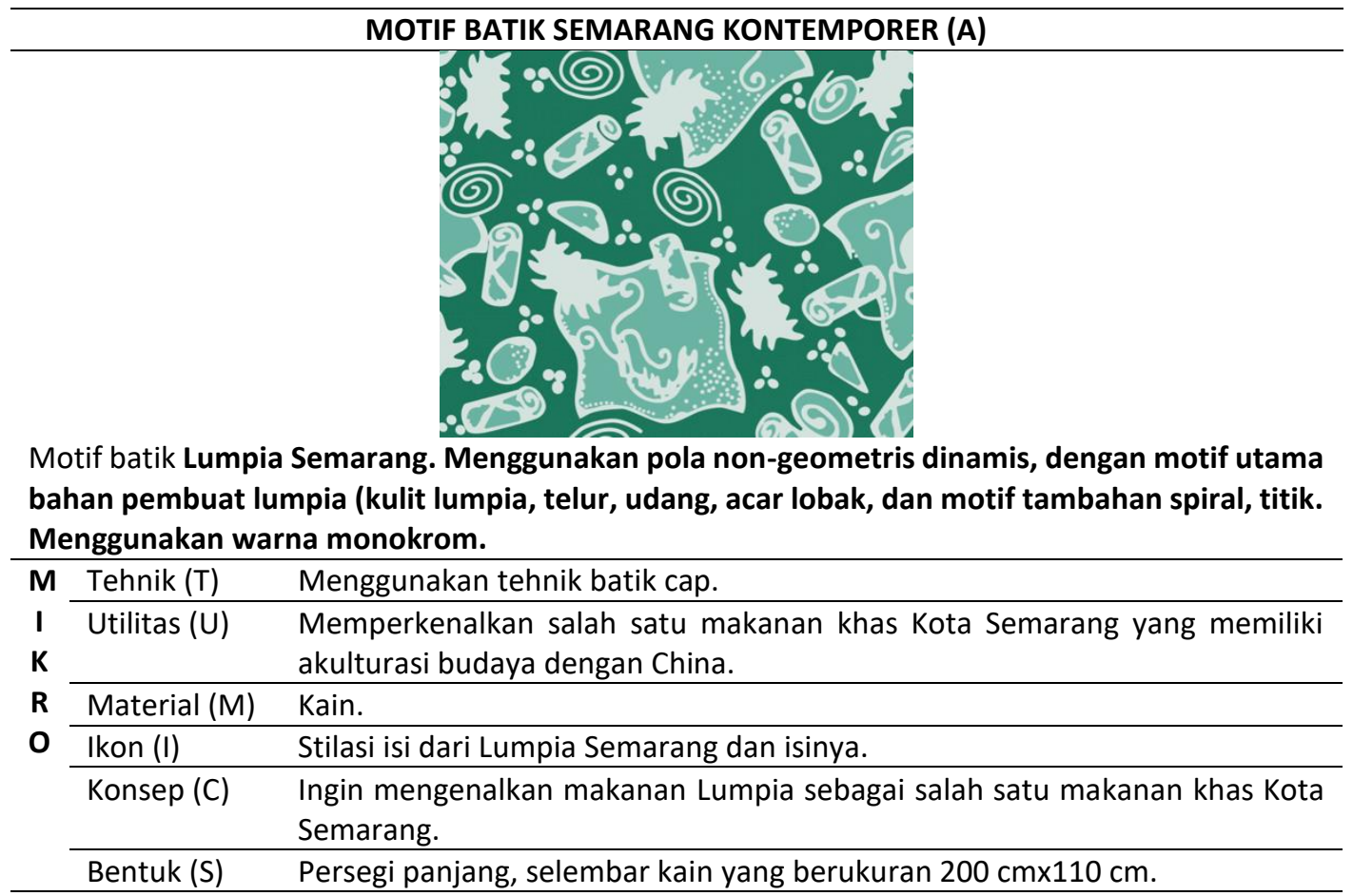




\begin{tabular}{lll}
\hline $\mathbf{M}$ & Ekonomi & Menambah varian motif batik, untuk dipasarkan. \\
\cline { 2 - 3 } $\mathbf{K}$ & Sosial & Melibatkan pegrajin batik cap. \\
\cline { 2 - 3 } $\mathbf{R}$ & Budaya & Mengenalkan makanan khas asal Kota Semarang melalui motif batik. \\
\cline { 2 - 3 } $\mathbf{O}$ & Ekologis & $\begin{array}{l}\text { Pada saat membuat motif pengrajin belum terlalu memikirkan motivasi } \\
\text { ekologis. Namun bila ingin lebih ramah lingkungan, pewarnaan kain bisa }\end{array}$ \\
\cline { 2 - 3 } & menggunakan propagul/ buah mangrove. \\
\hline Ekspresi-diri & $\begin{array}{l}\text { Pengrajin membuat berdasarkan permintaan dari pemilik usaha dan } \\
\text { ketentuan dari pemerintah untuk memasukan ikon khas Kota Semarang pada }\end{array}$ \\
\hline Survival & Produk kain batik. \\
& Pengrajin mengerjakan motif kain batik untuk bertahan hidup secara \\
\end{tabular}
sumber: Hartanti, 2019

Berikut ini adalah tahapan re-kreasi visual dari Motif Batik Lumpia Semarang menggunakan Bahasa rupa yang ditambahkan dengan augmented reality. Tahap pertama, mendata terlebih dahulu cerita yang akan dimasukkan dalam motion yang menggunakan AR. Cerita yang diangkat adalah cerita rakyat tentang asal usul Lumpia Semarang. Menceritakan seorang perantauan bernama Tjoa Thay Joe asal Fujian, China yang datang ke Semarang untuk menetap. Dia membuka bisnis makanan. Kemudian bertemulah Tjoa Thay Joe dengan mbak Wasih, asli Jawa tengah yang berjualan makanan yang serupa. Seiring waktu mereka saling jatuh cinta dan menikah dan menggabungkan resep makanan milik mereka berdua dan diberi nama Lumpia. Saat ini lumpia adalah salah satu makanan khas kota Semarang yang banyak dijual dengan beragam merek. Tahap kedua, motif Lumpia Semarang di-rekreasi dengan menggunakan cara bertutur Bahasa rupa RWD dan ditambahkan teknologi augmented Reality (AR)-Zappar untuk menceritakan legenda Lumpia Semarang dengan lebih detail dan menarik. Untuk menjalankan AR pada aplikasi Zappar dapat melalui tahapan di bawah ini:

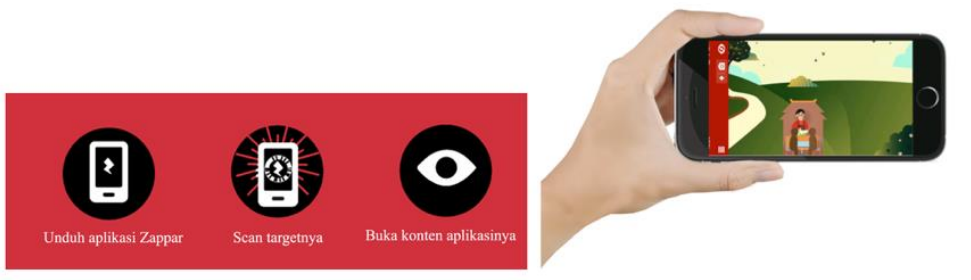

Gambar 3 Cara unduh aplikasi Zappar 

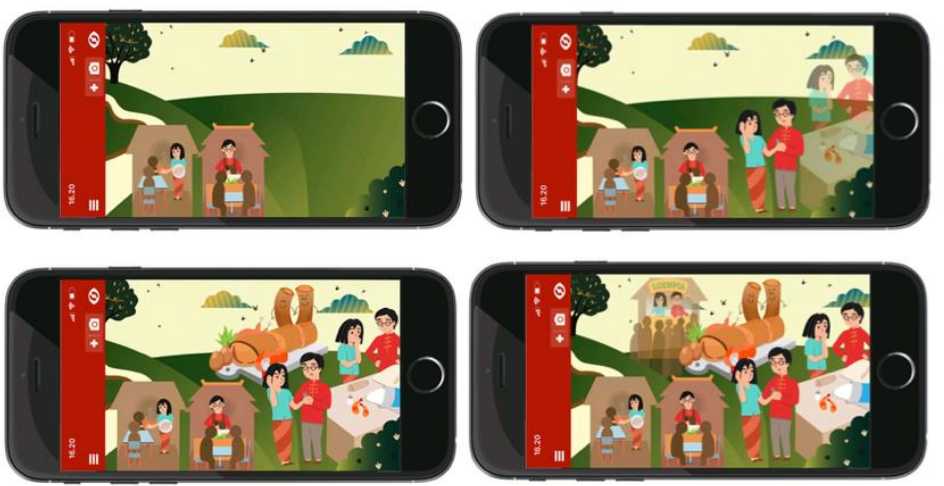

Gambar 4 Tahapan visual motion yang menceritakan asal usul Lumpia Semarang dengan menggunakan AR aplikasi Zappar.

Tabel 2 Pemetaan Visualisasi Legenda Lumpia Semarang yang ditambahkan teknologi Augmented Reality dengan metode ATUMICS

\begin{tabular}{|c|c|c|}
\hline \multicolumn{3}{|r|}{ MOTIF BATIK SEMARANG KONTEMPORER YANG SUDAH DI REKREASI (B) } \\
\hline \multicolumn{3}{|r|}{$\begin{array}{l}\text { Menggunakan teknik ilustrasi vektor, motion grafis untuk konten AR-nya. } \\
\text { untuk mengakses perlu download zappar terlebih dahulu. }\end{array}$} \\
\hline $\begin{array}{l}\mathbf{K} \\
\mathbf{R}\end{array}$ & Utilitas (U) & $\begin{array}{l}\text { Menceritakan legenda tentang Lumpia Semarang yang kaya akan budaya akulturasi } \\
\text { China dan Jawa tengah. }\end{array}$ \\
\hline \multirow[t]{4}{*}{0} & Material (M) & $\begin{array}{l}\text { Visualisasi dan Logo aplikasi Zappar untuk menjalankan AR-nya dapat dicetak pada } \\
\text { material berupa kertas dan kain. Akses AR-nya menggunakan dengan media digital, } \\
\text { seperti smartphone, tablet. }\end{array}$ \\
\hline & Ikon (I) & $\begin{array}{l}\text { Stilasi legenda Lumpia Semarang yang digambarkan dengan cara bertutur dan bahasa } \\
\text { rupa, berupa gambar gabungan dari prinsip RWD (Ruang Waktu Datar). }\end{array}$ \\
\hline & Konsep (C) & $\begin{array}{l}\text { Menceritakan legenda Lumpia Semarang sebagai makanan khas Kota Semarang yang } \\
\text { memiliki akulturasi budaya dengan China. }\end{array}$ \\
\hline & Bentuk (S) & $\begin{array}{l}\text { Bentuk mengikuti pengaplikasian medianya. Bila ilustrasi legenda Lumpia } \\
\text { Semarangnya akan dicetak maka bentuknya bisa dalam format apapun. Bila hanya } \\
\text { ingin menjalankan AR nya, bentuk adalah seukuran layar perangkat digital. }\end{array}$ \\
\hline
\end{tabular}




\begin{tabular}{lll}
\hline $\mathbf{M}$ & Ekonomi & Logo aplikasi AR dapat menjadi gimmick yang memberi daya tarik bila dimasukkan di \\
$\mathbf{A}$ & & media apapun, misal pada desain kemasan, kain, buku, sehingga dapat menambah \\
$\mathbf{K}$ & & nilai jual dengan interaktif media yang terlihat inovatif dan masa kini. \\
$\mathbf{R}$ & & Target market dari gimmick AR ini khususnya adalah generasi digital. \\
\cline { 2 - 3 } $\mathbf{0}$ & Sosial & Merangkul desainer dan generasi muda untuk lebih mengenal tentang legenda \\
& Lumpia Semarang. \\
\hline Budaya & Tidak hanya mengenalkan makanan khas asal Kota Semarang melalui motif batik \\
& namun juga legendanya yang berisi muatan akulturasi China dan Jawa tengah. \\
\hline Ekologis & AR bisa ditonton berulang kali, paperless dan lebih ramah lingkungan. \\
\hline Ekspresi-diri & Desainer dapat menggunakan gaya visual dan cara bertutur yang diinginkan. \\
& Penambahan teknologi AR sebagai bentuk ekspresi untuk memadukan teknologi dan \\
\hline \multicolumn{2}{c}{ Survival } & Dudaya daerah. \\
\hline
\end{tabular}
sumber: Hartanti, 2019

Logo aplikasi Zappar (Zappar code) dapat dicetakkan di berbagai media cetak seperti kemasan lumpia, kemasan kain batik, flyer, poster dan media cetak lainnya sehingga konten motion grafis yang terdapat di dalamnya dapat dilihat secara berulang kali.

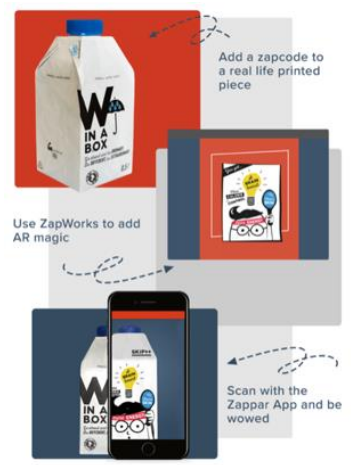

Gambar 5 Contoh penerapan Zappar code pada desain kemasan

Sumber: https://www.zappar.com
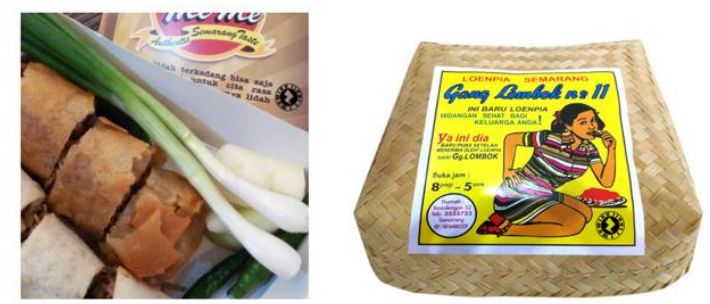

Gambar 6 Penerapan Zappar code pada kemasan Lumpia Semarang sumber: infomakan.com 
Tabel 3 Analisis Perbandingan motif Batik Lumpia Semarang sebelum dan sesudah re-kreasi

\begin{tabular}{|c|c|c|c|}
\hline & ATUMICS & A & B \\
\hline $\begin{array}{l}M \\
\mathbf{I} \\
\mathrm{K} \\
\mathrm{R}\end{array}$ & Tehnik (T) & $\begin{array}{l}\text { Teknik manual membutuhkan keahlian } \\
\text { khusus dan pelatihan ketrampilan dari } \\
\text { pengrajin batik yang saat ini sudah } \\
\text { sedikit jumlahnya. }\end{array}$ & $\begin{array}{l}\text { Teknik digital, membutuhkan } \\
\text { ketrampilan software desain digital, } \\
\text { relatif mudah untuk dipelajari bag } \\
\text { desainer generasi digital. }\end{array}$ \\
\hline \multirow[t]{5}{*}{0} & Utilitas (U) & $\begin{array}{l}\text { Mengenalkan Lumpia Semarang sebagai } \\
\text { salah satu motif batik Semarang. }\end{array}$ & $\begin{array}{l}\text { Mengenalkan Lumpia Semarang dan } \\
\text { legendanya. Bisa diisi dengan konten } \\
\text { tambahan yang dapat dikomersilkan. }\end{array}$ \\
\hline & Material (M) & Material terbatas pada kain. & $\begin{array}{l}\text { Dapat diterapkan diberbagai media } \\
\text { cetak dan diakses berulang-ulang } \\
\text { dengan media digital, sepert } \\
\text { smartphone, tablet. }\end{array}$ \\
\hline & Ikon (I) & $\begin{array}{l}\text { Lumpia Semarang dan isinya distilasikan } \\
\text { mengikuti pakem batik yang sudah ada. }\end{array}$ & $\begin{array}{l}\text { Perlu mempelajari teori visual } \\
\text { misalnya Bahasa rupa. Bisa juga } \\
\text { divisualkan dengan gaya gambar dan } \\
\text { cara bertutur yang berbeda, sehingga } \\
\text { lebih banyak pilihan. }\end{array}$ \\
\hline & Konsep (C) & $\begin{array}{l}\text { Hanya mengenalkan isi dari Lumpia } \\
\text { Semarang. }\end{array}$ & $\begin{array}{l}\text { Selain mengenalkan Lumpia } \\
\text { Semarang, juga mengenalkan } \\
\text { legenda Lumpia sebagai makanan } \\
\text { hasil budaya akulturasi khas Kota } \\
\text { Semarang. }\end{array}$ \\
\hline & Bentuk (S) & $\begin{array}{l}\text { Persegi panjang, ukuran kain batik pada } \\
\text { umumnya }\end{array}$ & $\begin{array}{l}\text { Bentuk mengikuti pengaplikasian } \\
\text { medianya. }\end{array}$ \\
\hline $\begin{array}{l}\text { M } \\
\text { A } \\
\text { K } \\
\text { R } \\
\text { O }\end{array}$ & Ekonomi & $\begin{array}{l}\text { Dibatasi hanya menjual kain batik yang } \\
\text { dibuat saja. }\end{array}$ & $\begin{array}{l}\text { Visualisasi legenda yang dalam } \\
\text { bentuk motion grafis dapat menjadi } \\
\text { gimmick sebagai promosi budaya } \\
\text { daerah, dengan target market } \\
\text { khususnya generasi digital. } \\
\text { Bisa diberikan content promosi } \\
\text { tambahan pada motion grafisnya. }\end{array}$ \\
\hline \multirow{5}{*}{$\mathbf{0}$} & Sosial & $\begin{array}{l}\text { Memberi penghasilan dan } \\
\text { keberlanjutan bagi Pengrajin Batik } \\
\text { Semarang. }\end{array}$ & $\begin{array}{l}\text { Mengenalkan budaya daerah pada } \\
\text { desainer dan masyarakat yang } \\
\text { belum mengenalnya. }\end{array}$ \\
\hline & Budaya & $\begin{array}{l}\text { Keberlanjutan salah satu budaya kuliner } \\
\text { kota Semarang. }\end{array}$ & $\begin{array}{l}\text { Keberlanjutan budaya daerah kota } \\
\text { Semarang melalui pendekatan media } \\
\text { yang baru. }\end{array}$ \\
\hline & Ekologis & $\begin{array}{l}\text { Bisa diupayakan untuk Eco friendly bila } \\
\text { pewarnaannya menggunakan pewarna } \\
\text { alami. }\end{array}$ & $\begin{array}{l}\text { Paperless, AR bisa diakses berulang- } \\
\text { ulang. }\end{array}$ \\
\hline & Ekspresi-diri & $\begin{array}{l}\text { Tidak ada, karena mengerjakan sesuai } \\
\text { pesanan. }\end{array}$ & $\begin{array}{l}\text { Ada, bisa disesuaikan dengan gaya } \\
\text { visual desainernya. }\end{array}$ \\
\hline & Survival & $\begin{array}{l}\text { Membatik untuk bertahan hidup secara } \\
\text { ekonomi. }\end{array}$ & $\begin{array}{l}\text { Mempertahankan legenda daerah } \\
\text { agar tetap dikenal oleh generasi saat } \\
\text { ini. }\end{array}$ \\
\hline
\end{tabular}


Hasil analisis pada tabel dapat dirangkumkan bahwa re-kreasi motif Batik Lumpia Semarang dapat dilakukan tanpa menghilangkan nilai kelokalannya. Dengan menggunakan cara bertutur visual yang sesuai pengetahuan tentang budaya daerah yang disampaikan menjadi lebih detail, hal ini juga sekaligus sebagai bentuk ekspresi diri dari desainer yang merancangnya. Penambahan teknologi AR merupakan salah satu bentuk kolaborasi budaya daerah dengan teknologi yang akan memberi fungsi tambahan sebagai gimmick yang memberi daya tarik khususnya bagi generasi digital untuk mengetahui budaya daerah yang disajikan dalam media baru yang dekat dengan keseharian mereka. Bentuk kolaborasi ini dapat diterapkan oleh budaya daerah asalkan mengandung muatan folklore cerita rakyat. Gambar dan logo aplikasi dapat diterapkan di berbagai media tercetak dan dapat diakses dengan mudah secara berulang kali.

\section{KESIMPULAN}

Melalui re-kreasi folklore pada motif Batik Semarang Kontemporer, Legenda kota Semarang dapat dikenalkan kembali melalui media baru pada generasi muda kota Semarang khususnya. Hal ini diharapkan akan memberi inspirasi bagi pengrajin batik Semarang untuk berkolaborasi dengan desainer digital untuk mere-kreasikan motif Batik Semarang lainnya dalam bentuk media yang baru. Dari sisi keberlanjutan, re-kreasi yang dilakukan dapat membuat motif Batik Semarang menjadi lebih menarik dan pengetahuan budaya tentang legenda akan bertambah detail, karena disampaikan dengan cara yang kreatif dan menggunakan media yang sesuai dengan masyarakat saat ini.

\section{PERNYATAAN PENGHARGAAN}

Penelitian ini merupakan kelanjutan dari riset dengan dana internal yang dikembangkan lebih lanjut dan dalam riset pendanaan hibah Ristek desentralisasi 
PTUPT tahun ke-2. Tim peneliti mengucapkan terimakasih kepada Universitas Kristen Maranatha dan Kementrian Ristek Dikti.

\section{DAFTAR PUSTAKA}

Agustin, DSY., 2011. Penurunan Rasa Cinta Budaya dan Nasionalisme Generasi Muda Akibat Globalisasi. Jurnal Sosial Humaniora. 4 (2). 177-185 DOI: 10.12962/j24433527.v4i2.632. Tersedia di http://iptek.its.ac.id/index.php/jsh/article/view/632/354 [1 Oktober 2019, 13.50]

Agustine, S., 2019. Kajian Desain Aplikasi Mobile Recruitment Bagi Pengguna Kelas Sosial Ekonomi Menengah Bawah. Institute Teknologi Bandung. Tersedia di https://digilib.itb.ac.id/index.php/gdl/search [20 Agustus 2019]

https://budaya-indonesia.org/Asal-Usul-dan-Cara-Membuat-Lumpia-Semarang [2 Oktober 2019]

Cerita Timun Mas Dalam Folklore.Tersedia di
http://elib.unikom.ac.id/files/disk1/582/jbptunikompp-gdl-likyardian29081-8-unikom_l-i.pdf. [25 Agustus 2018]

Gould, S., 2014. Can Augmented Reality Add Value to Print? Tersedia di https://www.targetmarketingmag.com/article/can-augmented-realityadd-value-print/all. [13 Agustus 2018]

Husamah, 2009. Mengusung Kembali Khazanah Identitas Budaya Bangsa. Jurnal Bestari 49. [1 Oktober 2019, 14.10]

http://www.infomakan.com/wp-content/uploads/2014/06/lumpia999.jpg. [2 Oktober 2019

Nugraha, A. 2012. Transforming Tradition: A Method for Maintaining Tradition in a Craft and Design Context. Helsinki: Unigrafia.

Seliriana, M., 2012. Perlindungan Hak Cipta Seni Batik Cirebon. Universitas Indonesia, Jakarta. Tersedia di http://lib.ui.ac.id/file?file=digital/20313805T\%2031747-Perlindungan\%20hak-full\%20text.pdf [25 Juli 2019] 
Tabrani, P. 2014. Proses Kreasi - Proses Belajar - Gambar Anak. Jakarta: Penerbit Erlangga.

Tabrani, P., 2009. Wimba Asal Usul dan Peruntukannya. Wimba, Jurnal Komunikasi Visual. 1(1). 1-7. Tersedia di http://journals.itb.ac.id/index.php/wimba/article/view/10914 [3 Oktober $2019,13.45]$

Yuliati, D., 2010. Mengungkap Sejarah dan Motif Batik Semarangan. Paramita 2(1).11-20. DOI: 10.15294/paramita. v20i1.1055. Tersedia di https://www.researchgate.net/publication/307789301_MENGUNGKAP_S EJARAH_DAN_MOTIF_BATIK_SEMARANGAN [25 Juli 2018, 13.00]

Wiley, K., 2017, From Your Phone to Your Home: An Augmented Reality Brand Experience for High-End Furniture, Thesis, Texas State University, San Marcos, Texas. Tersedia di https://digital.library.txstate.edu/bitstream/handle/10877/6730/Wiley_K endra_Thesis.pdf?sequence=1\&isAllowed=y. [25 Juli 2018] 